\title{
Investigation of Stacked Balanced-Fed Patch Antenna for Millimeter-Wave Application
}

\author{
Ilhem GHARBI ${ }^{1}$, Rim BARRAK ${ }^{1}$, Aliou DIALLO ${ }^{2}$, Jean-Marc RIBERO', \\ Hedi RAGAD ${ }^{3}$, Mourad MENIF ${ }^{l}$ \\ ${ }^{1}$ GRESCOM Laboratory, University of Carthage, Ariana, Tunisia \\ ${ }^{2}$ CNRS LEAT, Université Nice Côte d'Azur, Nice, France \\ ${ }^{3}$ CSEHF Laboratory, University of Tunis El Manar, Tunis, Tunisia
}

\{ilhem.gharbi, rim.barrak, mourad.menif\}@supcom.tn, \{jean-marc.ribero, aliou.diallo\}@unice.fr,hedi.ragad@gmail.com

Submitted January 9, 2020 / Accepted July 20, 2020

\begin{abstract}
A stacked patch antenna with balanced feed operating in millimeter-wave band is proposed in this paper. Initially, a single balanced-fed patch antenna is designed in three layers. Simulation results show that the proposed antenna enhances the cross-polarization and the radiation gain of the conventional aperture coupled patch antenna. A maximum gain of $6.8 \mathrm{dBi}$ is achieved with a bandwidth of $2 \mathrm{GHz}$ around $26 \mathrm{GHz}$. The stacked patch antenna was fabricated using $0.65 \mathrm{~mm}$ AR1000 and $0.787 \mathrm{~mm}$ RO5880 substrates. Measurement results of return loss agreed with the simulations and showed wide bandwidth, which is required for future $5 G$ communication terminals. To further increase the gain, we propose an integrated 8-element antenna array based on an 8-way Wilkinson power divider. The proposed design achieves a maximum gain of $14.1 \mathrm{dBi}$ at $26 \mathrm{GHz}$ with greatly reduced grating lobes and cross-polarization. The proposed antenna array represents a potential solution for the emerging $5 G$ wireless applications.
\end{abstract}

\section{Keywords}

Patch antenna array, 5G, aperture feed, Wilkinson power divider, $26 \mathrm{GHz}$ band, balanced feed

\section{Introduction}

Wireless data traffic has grown rapidly in the past few years and this trend is expected to continue over the next decade with the frequent use of videos and the release of the Internet of Things (IoT). To satisfy this demand, the fifth generation $(5 \mathrm{G})$ of mobile technology is being investigated. Number of frequency bands, especially in the millimeter wave band (mm-wave), were proposed as candidate frequencies to allow high-speed communication due to the large available bandwidths [1]. However, mm-wave communication suffers from some propagation issues, such as large path loss and shadowing, which can be overcome by directional and adaptive radiation pattern antennas.
Many research works were proposed at different levels from the device to the radio system and network architecture to support the communication in mm-wave frequency bands [2]. In [3], a mm-wave phased array transceiver for $5 \mathrm{G}$ fixed wireless access applications was developed for a frequency band around $30 \mathrm{GHz}$. In this RFfront-end, four key building blocks were addressed: high Power Amplifier (PA), Low Noise Amplifier (LNA), amplitude invariant phase shifter and phase invariant Variable Gain Amplifier (VGA). In [4], the authors presented a compact CMOS receiver front-end for multiband $5 \mathrm{G}$ massive multiple input multiple output (MIMO). Measurement results showed broadband operation ranging from 24.5 to $43.5 \mathrm{GHz}$.

To deliver $\mathrm{Gb} / \mathrm{s}$ data to multiple users with low latency and to achieve acceptable link budgets, 5G base stations and user equipment will rely on high performance antenna arrays. Microstrip patch antennas have been widely used because of their low profile and ease of fabrication. However, they showed some drawbacks, such as low gain and narrow bandwidth. Various techniques have been proposed to enhance antenna gain including the use of Substrate Integrated Waveguide (SIW) technology, superstrate layers, Electromagnetic Bandgap Structures (EBG) and antenna arrays [5-7]. In [5], quasi-annular SIW corrugated antenna is presented. A high gain up to $21.4 \mathrm{dBi}$ with a bandwidth of $2 \mathrm{GHz}$ is achieved for $30 \mathrm{GHz}$ band. In [6], a five-element patch array with a superstrate layer is proposed. A maximum gain of $13.4 \mathrm{dBi}$ and a bandwidth of 5.4 GHz ranging from $25.1 \mathrm{GHz}$ to $30.5 \mathrm{GHz}$ are achieved.

For size reduction purpose, antennas are generally fabricated in a multilayer structure. In [8], a dual-band stacked coupled patch antenna with bend parasitic elements is presented. It achieves a peak gain of $7.14 \mathrm{dBi}$ in the lower band $25.75-30.25 \mathrm{GHz}$ and $6.44 \mathrm{dBi}$ in the higher band $36.5-41.5 \mathrm{GHz}$.

In this paper, we focus on the design of new stacked patch antenna topology with balanced feed operating in $26 \mathrm{GHz}$ band. The proposed design is intended to reduce antenna size and side lobe interference. Then, in order to 


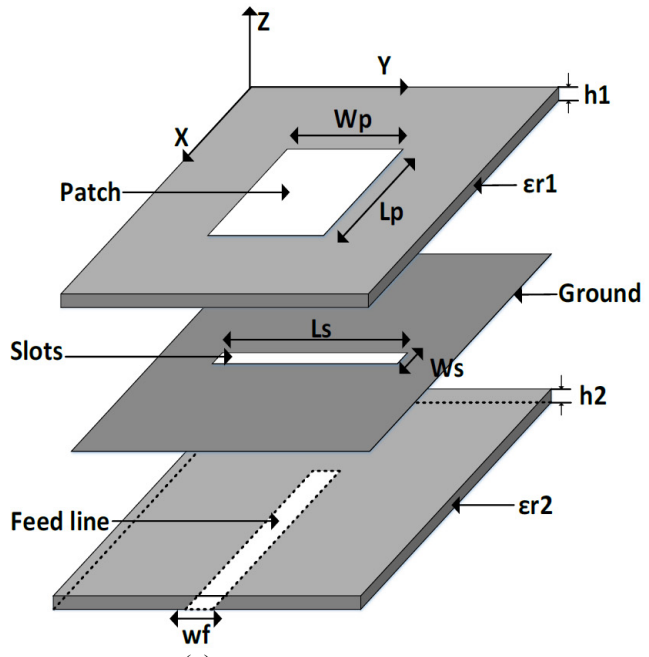

(a)

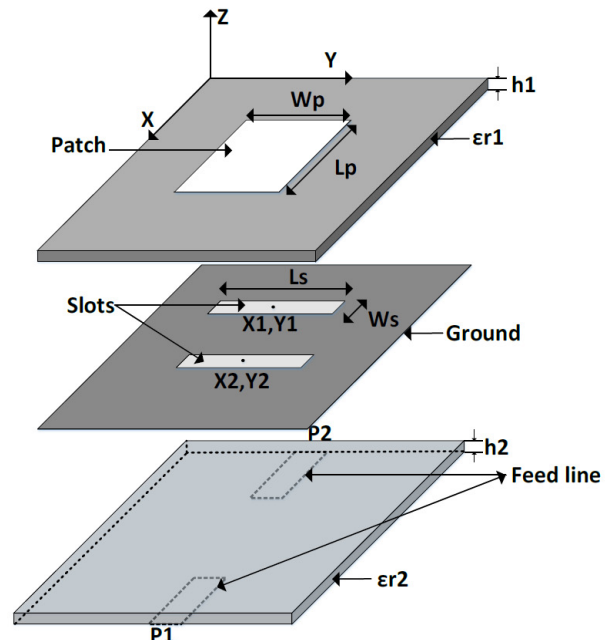

(b)

Fig. 1. Cross view of (a) aperture coupled patch antenna, (b) balanced-fed patch antenna.

improve the antenna directivity and gain, we propose an 8element antenna array fed by two out-of-phase 8-way power dividers.

The paper is organized as follows. In Sec. 2, the theory of the balanced-fed patch antenna and its advantages are given. Section 3 reports the stacked patch antenna topology and design followed by simulation and experimental results. The design and simulation results of the proposed 8-element balanced-fed patch antenna array are reported in Sec. 4. Lastly, Section 5 concludes this paper.

\section{Balanced-fed Patch Antenna Theory and Advantages}

The microstrip patch antenna is a narrow band structure. One of the keys to improving bandwidth is the use of aperture feed. While microstrip antennas are typically limited to bandwidths of $2 \%-5 \%$, aperture coupled antennas have demonstrated bandwidths of up to $30-50 \%$ with a stacked patch configuration [9]. The geometry of the aperture coupled patch antenna is shown in Fig. 1(a). The radiating microstrip patch antenna is etched on the top of the antenna substrate $\left(\varepsilon_{\mathrm{r} 1}, h_{1}\right)$, and the microstrip feed line is etched on the bottom of the feed substrate $\left(\varepsilon_{\mathrm{r} 2}, h_{2}\right)$. The two substrates are separated by a slotted ground plane.

The patch antenna length $L_{\mathrm{p}}$ and width $W_{\mathrm{p}}$ are calculated using the following formulas [10]:

$$
\begin{gathered}
W_{\mathrm{p}}=\frac{\lambda_{0}}{2 \sqrt{\frac{\varepsilon_{\mathrm{r} 1}+1}{2}}}, \\
L_{\mathrm{p}}=\frac{\lambda_{0}}{2 \sqrt{\varepsilon_{\mathrm{e}}}}-2 \Delta L, \\
\Delta L=0.412 h_{1} \frac{\left(\varepsilon_{\mathrm{e}}+0.3\right)\left(\frac{W_{\mathrm{p}}}{h_{1}}+0.264\right)}{\left(\varepsilon_{\mathrm{e}}-0.258\right)\left(\frac{W_{\mathrm{p}}}{h_{1}}+0.8\right)},
\end{gathered}
$$

$$
\varepsilon_{\mathrm{e}}=\frac{\varepsilon_{\mathrm{r} 1}+1}{2}+\frac{\varepsilon_{\mathrm{r} 1}-1}{2 \sqrt{1+12 \frac{h_{1}}{W_{\mathrm{p}}}}}
$$

where $h_{1}$ is the antenna substrate thickness, $\varepsilon_{\mathrm{e}}$ is the effective dielectric constant and $\lambda_{0}$ is the free-space wavelength at the resonant frequency.

The slot width $W_{\mathrm{s}}$ affects the coupling level between the feed line and the patch. The ratio of slot length $L_{\mathrm{s}}$ to its width $W_{\mathrm{s}}$ is about 0.1 [9].

The balanced-fed aperture coupled patch antenna topology is shown in Fig. 1(b). In this topology two $180^{\circ}$ out-of-phase lines excite the patch antenna differentially through two slots in the ground plane. The positions of the slots, leading to impedance matching, can be determined as [11]:

$$
\begin{gathered}
Y_{1}=Y_{2}=\frac{W_{\mathrm{p}}}{2}, \\
X_{1}=\frac{L_{\mathrm{p}}}{\pi} \cos ^{-1} \frac{W_{\mathrm{p}} \sqrt{5\left(\varepsilon_{\mathrm{r} 1}-1\right)}}{3 \varepsilon_{\mathrm{r} 1} L_{\mathrm{p}}}, \\
X_{2}=L_{\mathrm{p}}-X_{1}
\end{gathered}
$$

where $X_{1}$ is lower than $L_{\mathrm{p}} / 2$.

The condition for the excitation of the fundamental mode depends on the ratio of distance between the driving points to the free-space wavelength $\lambda_{0}$, which is given by [11]:

$$
\frac{X_{2}-X_{1}}{\lambda_{0}} \geq 0
$$

In order to compare the radiation performance of the two antenna topologies in Fig. 1, we have simulated their radiation gains at $26 \mathrm{GHz}$. The simulations were performed by finite element method (FEM) based on Ansoft HFSS software. Figure 2 shows the simulation results. As shown in Fig. 2, with one side feeding, the antenna features a direc- 


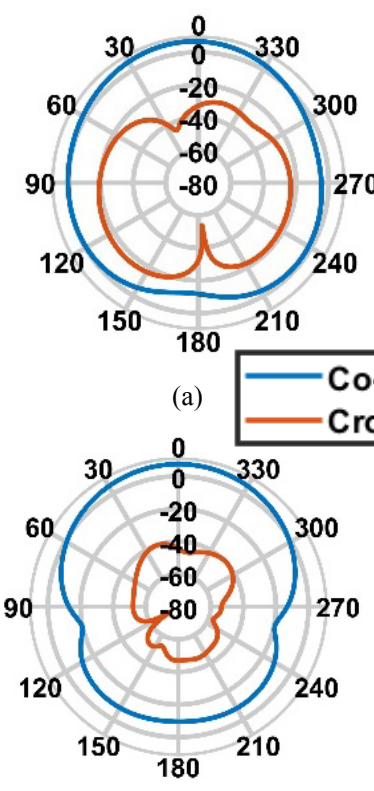

(c)

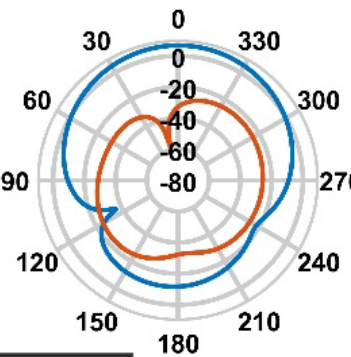

(b)

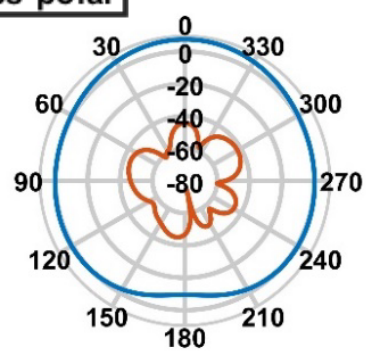

(d)
Fig. 2. Simulated radiation gains at $26 \mathrm{GHz}$ of the aperture patch antenna with one side feeding (a) in the plane (yoz), (b) in the plane (xoz) and with balanced feeding, (c) in the plane (yoz), (d) in the plane (xoz).

\begin{tabular}{|c|c|c|c|}
\hline & $\begin{array}{c}\text { Maximum } \\
\text { gain }[\mathrm{dBi}]\end{array}$ & $\begin{array}{c}\text { Maximum cross- } \\
\text { polar }[\mathrm{dBi}] \text { in the } \\
\text { plane (yoz) }\end{array}$ & $\begin{array}{c}\text { Maximum cross- } \\
\text { polar }[\mathrm{dBi} \text { in the } \\
\text { plane (xoz) }\end{array}$ \\
\hline $\begin{array}{c}\text { One side } \\
\text { feeding }\end{array}$ & 6.7 & -16.95 & -24.53 \\
\hline $\begin{array}{c}\text { Balanced } \\
\text { feeding }\end{array}$ & 7.71 & -40.21 & -39.93 \\
\hline
\end{tabular}

Tab. 1. Summary of the radiation gains.

tional radiation pattern with a maximum gain of $6.7 \mathrm{dBi}$ and a maximum cross-polarization of $-16.95 \mathrm{dBi}$. With balanced feeding, the antenna features a directional radiation pattern with a maximum gain of $7.71 \mathrm{dBi}$ and a crosspolarization of $-39.93 \mathrm{dBi}$. The radiation properties of the two topologies are summarized in Tab. 1.

We conclude about the balanced-fed antenna advantages, that it greatly enhances the cross-polarization and the radiation gain of the conventional aperture coupled patch antenna.

\section{Balanced-fed Stacked Patch Antenna Design}

This section reports the stacked patch antenna design followed by simulation and experimental results.

\subsection{Antenna Design}

The configuration of the proposed antenna is shown in Fig. 3. It consists of two layers of dielectric substrates and one metal layer. With the benefits of low dielectric constant and low loss tangent and to achieve a wide bandwidth, a $0.787 \mathrm{~mm} \operatorname{RO5880}\left(\varepsilon_{\mathrm{r} 1}=2.2\right.$ and $\left.\tan \delta=0.0009\right)$

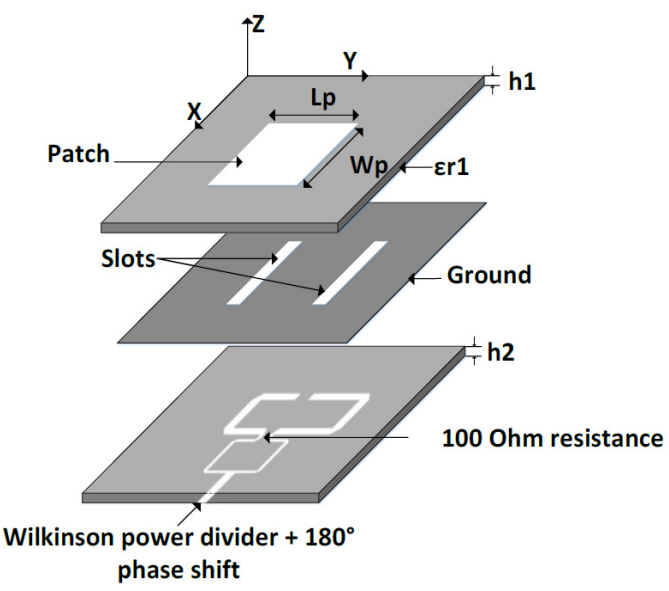

Fig. 3. Proposed stacked patch antenna topology.

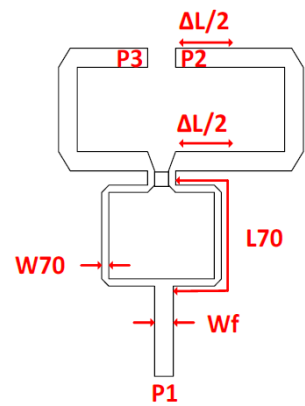

Fig. 4. Layout of the Wilkinson power divider plus the $180^{\circ}$ phase shifter.

\begin{tabular}{|c|c|}
\hline Parameter & Optimized value (mm) \\
\hline$L_{\mathrm{p}}$ & 3.25 \\
\hline$W_{\mathrm{p}}$ & 4 \\
\hline$L_{\mathrm{s}}$ & 2.5 \\
\hline$W_{\mathrm{s}}$ & 0.25 \\
\hline$W_{\mathrm{sub}}$ & 10 \\
\hline$L_{\mathrm{sub}}$ & 12 \\
\hline$W_{\mathrm{f}}$ & 0.57 \\
\hline$\Delta L$ & 2.2 \\
\hline$W_{70}$ & 0.2 \\
\hline$L_{70}$ & 5.4 \\
\hline
\end{tabular}

Tab. 2. Optimized parameters of the balanced-fed stacked patch antenna.

is used for antenna design. To reduce the feeding loss and to fulfill the miniaturization of the circuit, a $0.65 \mathrm{~mm}$ $\operatorname{AR} 1000\left(\varepsilon_{\mathrm{r} 2}=10\right.$ and $\left.\tan \delta=0.003\right)$ is used. Two slots etched on the ground plane are used as coupling apertures.

In order to split the power equally between the two opposite slots and to ensure the balanced feed, a Wilkinson power divider with a $180^{\circ}$ phase shifter is used to meet the design requirements. We have chosen the Wilkinson power divider because it provides better isolation between output ports and lower insertion loss than T-junction type splitter [9].

Figure 4 displays the design of the Wilkinson power divider with the $180^{\circ}$ phase shifter using Ansoft HFSS software. As illustrated, the power divider consists of three ports numbered P1, P2 and P3. It has a characteristic impedance $50 \Omega$. Ports 2 and 3 are composed of two quarter 
guided wavelength at the center frequency of the operating band $\left(\lambda_{\mathrm{g}} / 4\right)$ transmission lines with a characteristic impedance of $70.7 \Omega$ ended with $50 \Omega$ lines. The difference between the output transmission lines must be a half wavelength to ensure $180^{\circ}$ phase shift. The output resistance $100 \Omega$ is used to isolate output ports.

Table 2 depicts the optimized parameters for the Wilkinson power divider and the proposed balanced-fed patch antenna. $\Delta L$ refers to the difference between the output transmission lines of the phase shifter and $W_{\text {sub }}$ and $L_{\text {sub }}$ refer to the substrate width and length, respectively.

\subsection{Simulation Results}

This section reports the simulation results of the proposed stacked patch antenna. First, S-parameter simulations of the Wilkinson power divider with the phase shifter are analyzed, then, the overall performance of the proposed antenna is presented. Figure 5 displays the S-parameters of the Wilkinson power divider with the $180^{\circ}$ phase shifter. As shown, the circuit shows a good performance in terms of insertion loss, matching and isolation over the band frequency $24.5-26.5 \mathrm{GHz}$. The $\mathrm{S} 11$ is about $-12.5 \mathrm{~dB}$ at $26 \mathrm{GHz}$. The S22 and S33 are better than $-15 \mathrm{~dB}$. The insertion losses $(\mathrm{S} 21, \mathrm{~S} 31)$ are better than $-4.9 \mathrm{~dB}$ and the isolation between the output ports is better than $-15 \mathrm{~dB}$ at $26 \mathrm{GHz}$.

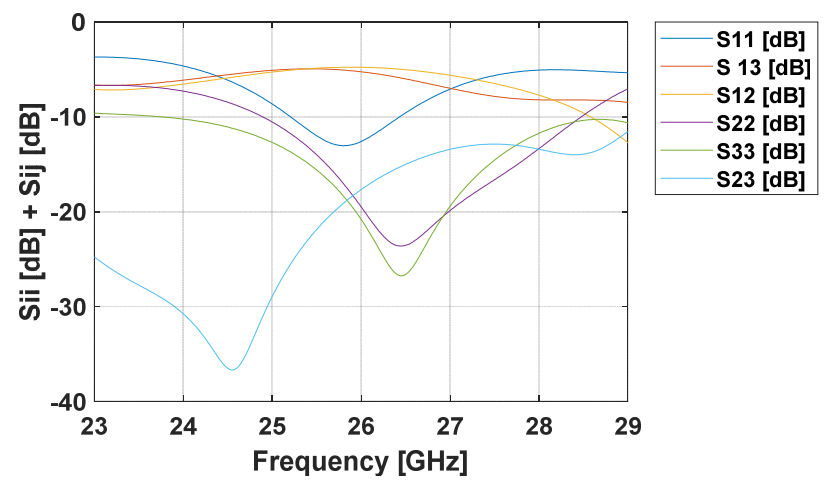

Fig. 5. S-parameters of the Wilkinson power divider plus the $180^{\circ}$ phase shifter.

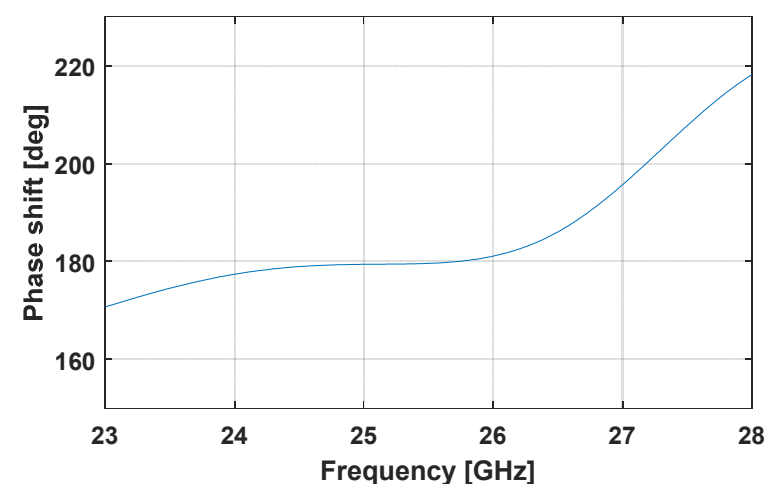

Fig. 6. Output phase shift of the Wilkinson power divider plus the $180^{\circ}$ phase shifter.

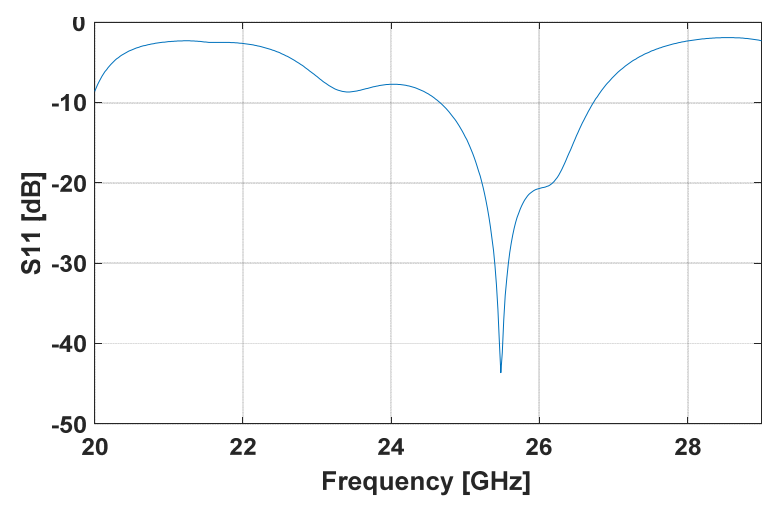

Fig. 7. Return loss of the balanced-fed stacked patch antenna.

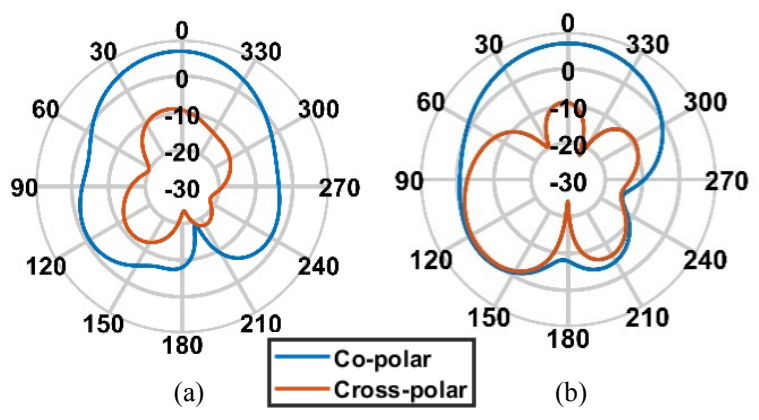

Fig. 8. Polar and cross-polar radiation pattern at $25.7 \mathrm{GHz}$ in (a) the yoz plane, (b) in the xoz plane.

Figure 6 shows the phase shift between the Wilkinson power divider output ports. As depicted, the phase shift between the output ports of the Wilkinson power divider plus the $180^{\circ}$ phase shifter is about $179.5 \pm 5^{\circ}$ along the band $23.5-26.8 \mathrm{GHz}$.

The return loss and the radiation gain of the proposed antenna are shown in Fig. 7 and Fig. 8, respectively. According to the simulation results, the proposed patch antenna is well matched at $25.7 \mathrm{GHz}$ and covers a bandwidth of $2.06 \mathrm{GHz}$ ranging from $24.66-26.72 \mathrm{GHz}$.

The antenna achieves a gain up to $6.86 \mathrm{dBi}$ and a maximum cross-polarization of $-1.1 \mathrm{dBi}$ and $-8.67 \mathrm{dBi}$ respectively in the (xoz) and (yoz) planes.

\subsection{Fabrication and Measurement Results}

In order to validate the simulated results, a prototype of the proposed antenna is fabricated and measured. Figure 9 illustrates the fabricated antenna structure. Figures 9(a) and 9(b) are photographs of the top and bottom layers respectively. The two layers were stacked up. Appropriate alignment and stacking of the layers are essential to achieve good performances. The measured return loss of the antenna was performed with the Rohde and Schwarz ZVA Vector Network Analyzer.

Figure 10 shows the simulated and measured return loss of the proposed stacked patch antenna. The 10-dB bandwidth of the proposed patch antenna is measured and it is from 23.5 to $29 \mathrm{GHz}(21.15 \%)$ resulting in a wide band- 


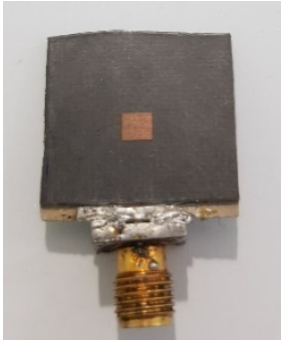

(a)

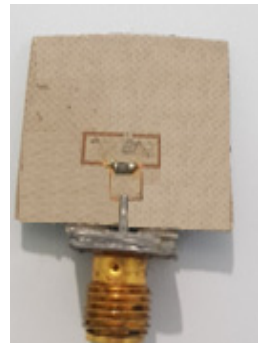

(b)
Fig. 9. Photo of the fabricated antenna (a) top view, (b) bottom view.

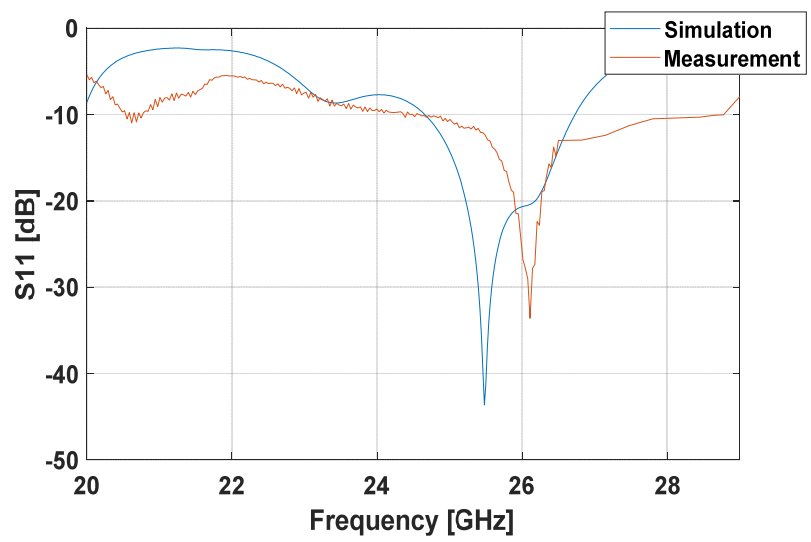

Fig. 10. Simulated and measured return loss of the balancedfed stacked patch antenna.

width which is required for future $5 \mathrm{G}$ communication terminals. The frequency shift can be due to the manufacturing process that can cause an increase in the thickness of the substrate, a change in the effective permittivity and an air gap problem when stacking the layers.

To further improve the cross-polarization level and the peak gain of the proposed patch antenna, we have built a $1 \times 8$ patch antenna array which will be discussed in the next section.

\section{Fed-balanced Stacked Patch Antenna Array Design}

Based on the single element designed in the previous section and for the purpose to build a compact integrated antenna array to achieve higher gain with reduced grating lobes and back radiation, we built an 8-element antenna array. In this section, we will start by evaluating the balanced feed performance, then, the 8-way Wilkinson power divider will be analyzed. Finally, we will present the simulated radiation gains in the $\mathrm{E}$ and $\mathrm{H}$ planes of the 8-element antenna array.

\subsection{Balanced Feeding Simulation}

In order to simulate the antenna array with balanced feed, 16 feed ports (P1 to P8 and P1' to P8') were considered with equal amplitudes as presented in Fig. 11. Each

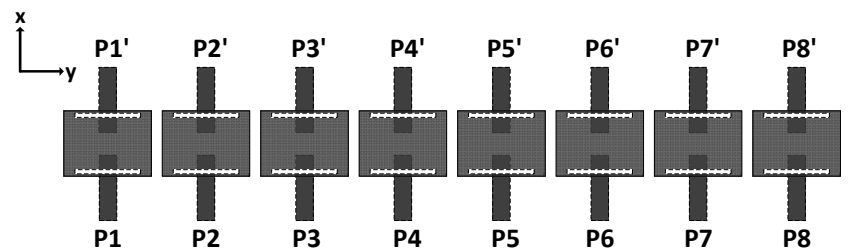

Fig. 11. Aligned balanced-fed patch antenna array.

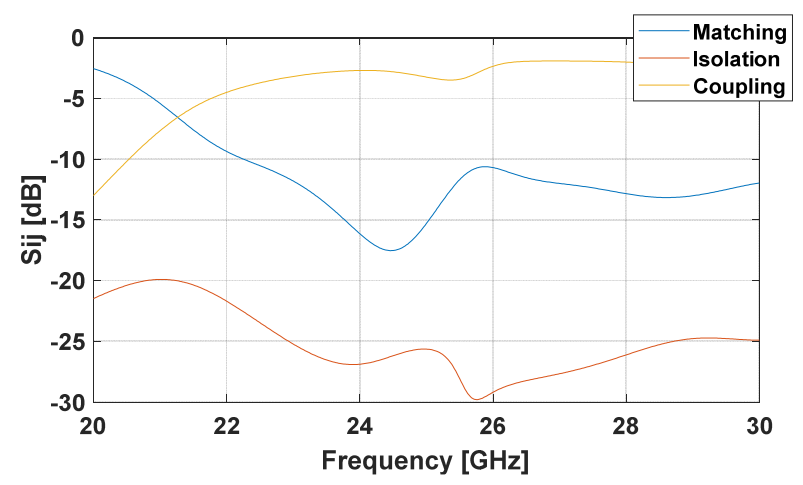

Fig. 12. Isolation and matching parameters of the balanced-fed patch antenna array.

opposite port must be $180^{\circ}$ out-of-phase. The distance between the antennas is selected to be $6 \mathrm{~mm}\left(0.52 \lambda_{0}\right.$ at $26 \mathrm{GHz}$ ). With this choice, the maximum gain is achieved in the normal direction $\theta=0^{\circ}$. The designed array is shown in Fig. 11. Figure 12 shows the simulated return loss over all ports, the coupling and the isolation between them. A good matching Sii $\left(i=1, \ldots, 8, i=1, \ldots, 8^{\prime}\right)$ is obtained for all the ports. The strong coupling between two opposite ports (Sii') can be resolved by using two separate 8-way Wilkinson power dividers, one for the $i$ ports $(1,2, \ldots, 8)$ and another for the $i$ ' ports $\left(1^{\prime}, 2\right.$ ', ...8').

The two dividers must be $180^{\circ}$ out-of-phase to have the maximum gain in the direction $\theta=0^{\circ}$. The isolation between nearest two ports $(\mathrm{P} i$ and $\mathrm{P}(i+1)$ or $\mathrm{P} i$ ' and $\left.\mathrm{P}\left(i^{\prime}+1\right)\right)$ is more than $20 \mathrm{~dB}$ within a wide bandwidth.

\subsection{8-way Wilkinson Power Divider Design}

Figure 13 shows the proposed 8-way Wilkinson power divider designed at $26 \mathrm{GHz}$, in which the input port is split up into 8 branches of impedance transformer. The divider is printed on a $0.65 \mathrm{~mm}$ AR1000 substrate and has 9 ports with port 1 as input port and ports from 2 to 9 as output ports. All the ports are matched to a characteristics impedance of $Z_{0}=50 \Omega$. The characteristic impedance transformer is $Z_{1}=70.7 \Omega$ and its length is a quarter-guided wavelength at the center frequency of the operating band. The value of the resistor is $R=100 \Omega$. The distance between two adjacent output ports is the same as between two adjacent elements of the antenna array. The optimized parameters of the 8-way power divider are summarized in Tab. 3. The simulated S-parameters of the 8-way power divider are shown in Fig. 14. The return loss at the input port $\mathrm{P} 1$ is below $-10 \mathrm{~dB}$ at $26.3 \mathrm{GHz}$. 
The return loss at the output ports $\mathrm{P} i(i=2, \ldots, 9)$ are below $-10 \mathrm{~dB}$ across a frequency band ranging from 26.24 to $26.5 \mathrm{GHz}$. The circuit achieves insertion losses $\mathrm{S} 1 i$, $i=2, \ldots, 9$ better than $-10.2 \mathrm{~dB}$ across the frequency band 26-27 GHz. Moreover, the circuit features a good isolation between the adjacent ports below $-15 \mathrm{~dB}$ in a frequency band ranging from $25-27.7 \mathrm{GHz}$.

Figures 15 and 16 show the phase and amplitude imbalance between the divider output ports, respectively. The phase difference is lower than $5^{\circ}$ at $26 \mathrm{GHz}$. From $23 \mathrm{GHz}$

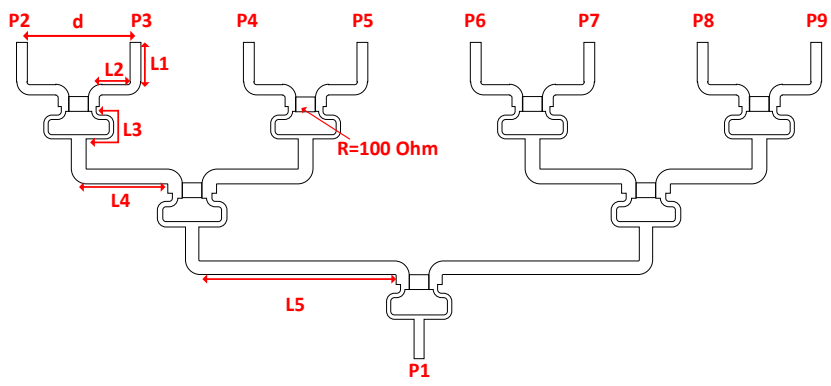

Fig. 13. 8-way Wilkinson power divider layout.

\begin{tabular}{|c|c|}
\hline Parameter & Value (mm) \\
\hline$L 1$ & 2 \\
\hline$L 2$ & 1.32 \\
\hline$L 3$ & 3.05 \\
\hline$L 4$ & 4.11 \\
\hline$L 5$ & 10 \\
\hline$d$ & 6 \\
\hline
\end{tabular}

Tab. 3. Optimized parameters of the 8 -way power divider.

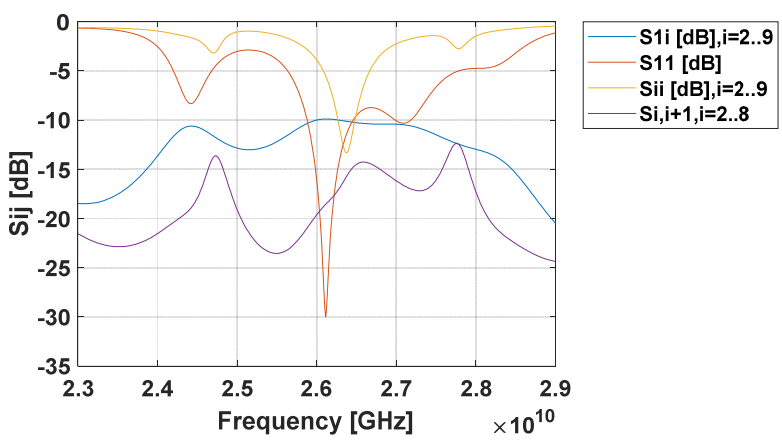

Fig. 14. S parameters of the 8-way power divider.

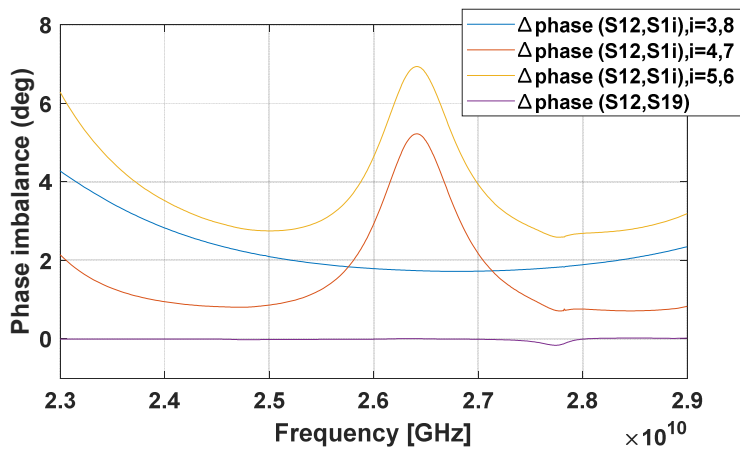

Fig. 15. Phase imbalance between the power divider output ports.

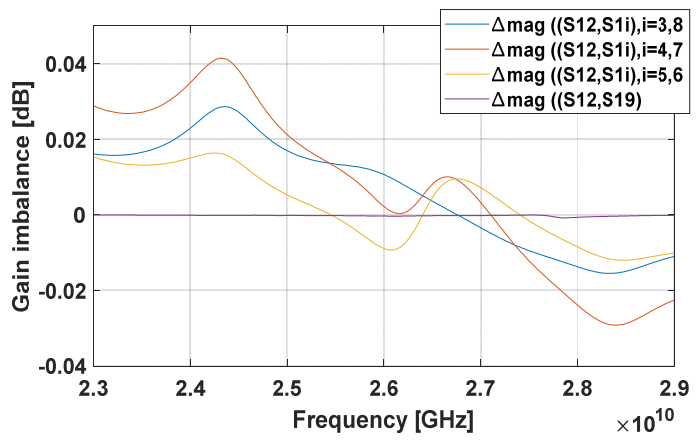

Fig. 16. Amplitude imbalance between the power divider output ports.

to $29 \mathrm{GHz}$, the amplitude imbalance between two different output ports is lower than $0.05 \mathrm{~dB}$. The highest phase error is observed at $26.5 \mathrm{GHz}$ with $6.9^{\circ}$.

\subsection{Antenna Array Simulation Results}

Based on the balanced antenna array and the 8-way Wilkinson power divider designed previously, we built the integrated eight-element antenna array shown in Fig. 17, where ports 1 and 2 are $180^{\circ}$ out-of-phase. The 8 -way power divider and the antenna are printed on the same AR1000 and RO5880 Rogers substrates used to design the balanced-fed single antenna. The antenna array occupies a volume of $45 \mathrm{~mm} \times 36 \mathrm{~mm} \times 1.542 \mathrm{~mm}$.

Figure 18 shows the co-polar and cross-polar pattern gain in the H-plane and E-plane at $26 \mathrm{GHz}$ of the proposed integrated antenna array.

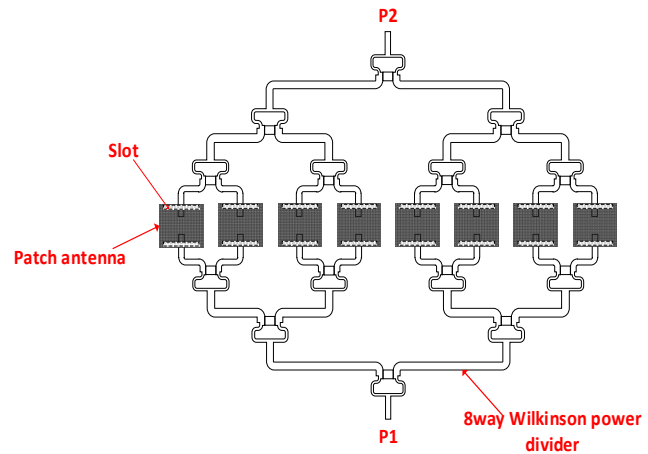

Fig. 17. Geometry of the integrated fed-balanced patch antenna array.

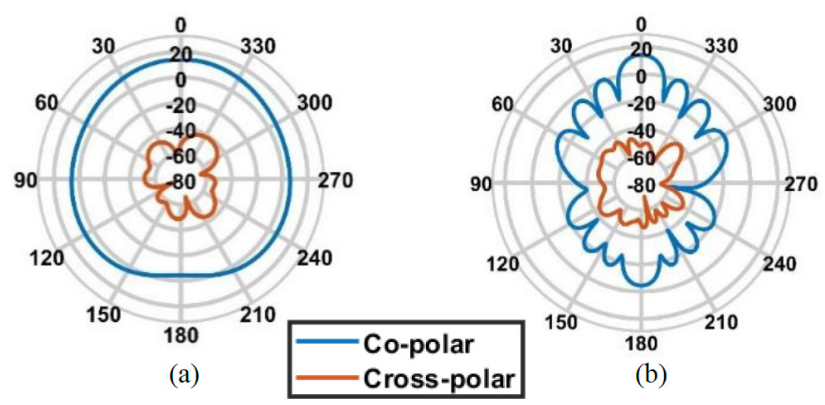

Fig. 18. Simulated radiation pattern at $26 \mathrm{GHz}$ of the fedbalanced stacked patch antenna array (a) in the plane (xoz), (b) in the plane (yoz). 


\begin{tabular}{|c|c|c|c|c|c|c|c|c|}
\hline Ref. & $\begin{array}{c}\text { Frequency } \\
{[\mathbf{G H z}]}\end{array}$ & Antenna topology & $\begin{array}{c}\text { Number } \\
\text { of } \\
\text { elements }\end{array}$ & $\begin{array}{c}\text { Gain } \\
{[\mathbf{d B i}]}\end{array}$ & $\begin{array}{c}\text { SLL } \\
\text { [dBi] }\end{array}$ & $\begin{array}{c}\text { Cross- } \\
\text { polar } \\
{[\mathbf{d B i}]}\end{array}$ & Size [mm] & Complexity \\
\hline$[\mathbf{1 2}]$ & 26 & Vivaldi antenna array & $1 \times 8$ & 11.32 & -10 & NA & $60 \times 28.57 \times 0.787$ & moderate \\
\hline$[\mathbf{1 3}]$ & 30 & Slot array with SIW & $4 \times 4$ & 15.9 & -10 & NA & $45 \times 165$ & moderate \\
\hline$[\mathbf{1 4}]$ & $27-29$ & A palm-sized antenna & $4 \times 4$ & 9 & $\sim 2$ & NA & $70 \times 40 \times 0.254$ & moderate \\
\hline$[\mathbf{1 5}]$ & 30 & SIW based monopoles & 8 & 12.3 & NA & NA & $23 \times 49 \times 1.524$ & simple \\
\hline$[\mathbf{1 6}]$ & 28 & $\begin{array}{c}\text { SIW dual-slot-fed patch } \\
\text { structure }\end{array}$ & $4 \times 4$ & 19.1 & -11.5 & -25 & $\sim 30 \times 30 \times 1.51$ & complex \\
\hline $\begin{array}{c}\text { This } \\
\text { work }\end{array}$ & 26 & $\begin{array}{c}\text { Stacked antenna array with } \\
\text { double excitation }\end{array}$ & 8 & 14.1 & 0.3 & -40 & $45 \times 36 \times 1.542$ & moderate \\
\hline
\end{tabular}

Tab. 4. Comparison with state of the art antenna array in mm-wave band.

As can be seen, we obtain good performances in terms of the main beam, the back radiation and the side lobe levels. The integrated eight element antenna array achieves a high gain of $14.1 \mathrm{dBi}$. The back radiation is about $-4.45 \mathrm{dBi}$, the maximum side lobe level is lower than $0.3 \mathrm{dBi}$ and the maximum cross polar is lower than $-40 \mathrm{dBi}$ which makes the antenna array very efficient to focus in one direction for $\mathrm{mm}$-wave bands. Moreover, the proposed antenna array offers a narrow beam width of $13^{\circ}$, which is an advantage for point-to-point communications.

Table 4 presents a comparison of the proposed antenna array performances with recently published works in mm-wave band. The 8-element antenna proposed in [12] achieves low gain of $11.32 \mathrm{dBi}$ in comparison to our work. Despite the use of a large number of radiating elements (16 elements) in [13], the antenna array achieves only $15.9 \mathrm{dBi}$. In [14], a palm sized antenna is proposed clutched by four multiple-input-multiple-output chip antennas and achieves a gain of $9 \mathrm{dBi}$. In [15], authors used monopole antenna to yield a compact configuration $(23 \mathrm{~mm} \times 49 \mathrm{~mm} \times 1.524 \mathrm{~mm})$ at $30 \mathrm{GHz}$ but the 8 -element antenna achieves only a gain of $12.3 \mathrm{dBi}$ compared with our work. Although the antenna array developed in [16] achieves a high gain with reduced side lobe level (SLL) and cross-polarization, the proposed antenna seems relatively complex. Thanks to the balanced feed, better gain and cross-polar radiation performances are achieved in this work compared to others works in the same field. These promising features make the proposed antenna array a viable solution for $5 \mathrm{G}$ applications. Therefore, designing a large antenna array using the balanced feed can produce desirable radiation performance for practical deployment.

\section{Conclusion}

In this paper, a novel stacked patch antenna with balanced feed is proposed in $26 \mathrm{GHz}$ band while maintaining good performances of bandwidth, gain and cross polar radiation. The antenna bandwidth is about $2.06 \mathrm{GHz}$ (24.66-26.72 GHz) and shows a compact size of $10 \times 12 \mathrm{~mm}^{2}$.Measurement results of return loss agreed with the simulation and show wide bandwidth which is required for future $5 \mathrm{G}$ mobile phones. Based on the designed patch antenna, we proposed an integrated 8-element antenna array. The proposed topology achieves a maximum gain of $14.1 \mathrm{dBi}$ while maintaining reduced secondary side lobes level and back radiation. The proposed array antenna could be a good candidate for the future $5 \mathrm{G}$ applications and can integrate beam-scanning capability.

\section{Acknowledgments}

The authors would like to thank the LEAT Laboratory at University of Nice Côte d'Azur, France for its support in measurements.

\section{References}

[1] RAPPAPORT, T. S., XING, Y., MACCARTNEY, G. R., et al. Overview of millimeter wave communications for fifth-generation (5G) wireless networks - With a focus on propagation models. IEEE Transactions on Antennas and Propagation, 2017, vol. 65, no. 12. p. 6213-6230. DOI: 10.1109/TAP.2017.2734243

[2] XU, X., LIU, M., XIONG, J., et al. Key technology and application of millimeter wave communications for 5G: A survey. Cluster Computing, 2019, vol.22, p. S12997-S13009. DOI: 10.1007/s10586-018-1831-X

[3] ZHAO, D., ZHANG, J., YI, Y., et al. 5G millimeter-wave phasedarray transceiver: System considerations and circuit implementations. In Proceeding of the IEEE International Symposium on Circuits and Systems (ISCAS). Sapporo (Japan), 2019, p. 1-4. DOI: 10.1109/ISCAS.2019.8702530

[4] HUANG, M. Y., CHI, T., LI, S., et al. A $24.5-43.5-\mathrm{GHz}$ ultracompact CMOS receiver front end with calibration-free instantaneous full-band image rejection for multiband $5 \mathrm{G}$ massive MIMO. IEEE Journal of Solid-State Circuits, 2020, vol. 55, no. 5, p. 1177-1186. DOI: 10.1109/JSSC.2019.2959495

[5] WU, Z., LIU, J., ZHANG, J., et al. Design of a Ka-band high-gain antenna with the quasi-annular SIW corrugated technique. IEEE Antennas and Wireless Propagation Letters, 2019, vol. 18, no. 5, p. 1001-1005. DOI: 10.1109/LAWP.2019.2907527

[6] FARHAT, S., ARSHAT, F., AMIN, Y., et al. Wideband patch array antenna using superstrate configuration for future $5 \mathrm{G}$ applications. Turkish Journal of Electrical Engineering and Computer Sciences, 2020, vol. 28, p. 1673-1685. DOI: 10.3906/elk-1910-160

[7] CHENG, C., CHEN, J. P., SU, H. L., et al. A wideband square-slot antenna array with superstrate and electromagnetic bandgap 
reflector for $60-\mathrm{GHz}$ applications. IEEE Transactions on Antennas and Propagation, 2017, vol. 65, no. 9, p. 4618-4625. DOI: 10.1109/TAP.2017.2729160

[8] STANLEY, M., HUANG, Y., WANG, H., et al. A dual-band dualpolarised stacked patch antenna for $28 \mathrm{GHz}$ and $39 \mathrm{GHz} 5 \mathrm{G}$ millimetre-wave communication. In Proceedings of 13th European Conference on Antennas and Propagation (EuCAP). Krakow (Poland), 2019, p. 1-4.

[9] POZAR, D. M. Microwave Engineering. $2^{\text {nd }}$ ed. New York: Wiley, 1998. ISBN: 0-471-17096-8

[10] BALANIS, C. A. Antenna Theory: Analysis and Design. $3^{\text {rd }}$ ed. Wiley- Interscience, 2005. ISBN: 978-0471667827

[11] ZHANG, Y. P. Design and experiment on differentially driven microstrip antennas. IEEE Transactions on Antennas and Propagation, 2007, vol. 55, no. 10, p. 2701-2708. DOI: 10.1109/TAP.2007.905832

[12] ZHU, S., LIU, H., CHEN, Z., et al. A compact gain-enhanced Vivaldi antenna array with suppressed mutual coupling for $5 \mathrm{G} \mathrm{mm}$ wave application. IEEE Antennas and Wireless Propagation Letters, 2018, vol. 17, no. 5, p. 776-779. DOI: 10.1109/LAWP.2018.2816038

[13] LIAN, J. W., BAN, Y. L., YANG, Q. L., et al. Planar millimeterwave 2-D beam-scanning multibeam array antenna fed by compact SIW beam-forming network. IEEE Transactions on Antennas and Propagation, 2018, vol. 66, no. 3, p. 1299-1310. DOI: 10.1109/TAP.2018.2797873

[14] LEE, C., KHATTAK, M. K., KAHNG, S. Wideband 5G beamforming printed array clutched by LTE-A $4 \times 4$-multipleinput multiple-output antennas with high isolation. IET Microwaves, Antennas and Propagation, 2018, vol. 12, no. 8, p. 1407-1413. DOI: 10.1049/IET-MAP.2017.0946

[15] DI PAOLA, C., ZHAO, K., ZHANG, S., et al. SIW multibeam antenna array at $30 \mathrm{GHz}$ for $5 \mathrm{G}$ mobile devices. IEEE Access, 2019, vol. 7, p. 73157-73164. DOI: 10.1109/ACCESS.2019.2919579

[16] JIN, H., CHE, W., CHIN, K. S., et al. Millimeter-wave TE20-mode SIW dual-slot-fed patch antenna array with a compact differential feeding network. IEEE Transactions on Antennas and Propagation, 2018, vol. 66, no. 1, p. 456-461. DOI: 10.1109/TAP.2017.2767644

\section{About the Authors ...}

Ilhem GHARBI received her engineering diploma in Telecommunication in 2016 from the National Engineering School of Gabes (ENIG), Tunisia and is currently pursuing her Ph.D. at the Higher Engineering School of Communication of Tunis (SUP'COM). Her research interests are in the areas of reconfigurable antennas for $5 \mathrm{G}$ applications.
Rim BARRAK received the B.S. degree in Circuits and Systems from the Polytechnic School of Tunisia, 2000, and the M.S. degree in Electrical Engineering at the Universite Laval, PQ, Canada, in the field of optical fiber communications. She is currently an Assistant Professor in Telecommunication and member of GRESCOM (Research Laboratory at Sup'COM). Her research interests are in the areas of software radio receiver architectures, design of reconfigurable multiband RF filters and antennas and design of intelligent RF receivers for wireless communication and GNSS positioning systems.

Mourad MENIF received the B.S.E.E., M.S.E.E., and D.E.A. degrees from the National Engineering School of Tunis (ENIT) and the Ph.D. degree in Electrical Engineering at the Universite Laval, PQ, Canada, in the field of optical fiber communications. He is currently a Professor in telecommunication and member of GRESCOM. His research interests include transient gain analysis of EDFA's fed by high speed, self-similar, and heavy traffic for WDM long-haul and access networks.

Hedi RAGAD received his M.S. degree in Electronic Engineering from Marne La Vallée University, France, in 2007, and the Ph.D. degree from University of Nantes, France. He is currently an Assistant Professor at the Faculty of Science of Tunis (FST), University el-Manar His research interests include dielectric resonator, antennas, and passive RF devices.

Jean-Marc RIBERO is currently a Professor at the Université Nice Côte d'Azur. He is deputy director of the Electronics Antennas and Telecommunications Laboratory (LEAT UMR CNRS 7248). His research activities relate to the design of multistandard miniature antennas, reconfigurable structures in order to improve the communicative aspect of small objects while taking into account existing communication standards and finally the design of antennas based on new materials

Aliou DIALLO received the B.S. and M.S. degrees in Electronics, Electrical Engineering, and Automatics, with specialization in electronics, and the D.E.A. degree, with specialization in propagation, telecommunications, and tele detection, from the University of Nice, Sophia-Antipolis, France, in 2002, 2003, and 2004, respectively, He received the Ph.D. degree from the University of Nice. He is also an Assistant Professor at the University of Nice Côte d'Azur. His major research area is antenna design for wireless communications. 